\title{
Impact of Temperature on Power Density in Closed- Loop Pressure Retarded Osmosis for Grid Storage
}

\author{
Daniel D. Anastasio ${ }^{a}$, Jason T. Arena ${ }^{a}$, Emily A. Cole ${ }^{b}$, Jeffrey R. McCutcheon ${ }^{a^{*}}$ \\ ${ }^{\mathrm{a} D e p a r t m e n t ~ o f ~ C h e m i c a l ~ \& ~ B i o m o l e c u l a r ~ E n g i n e e r i n g, ~ U n i v e r s i t y ~ o f ~ C o n n e c t i c u t, ~ S t o r r s, ~ C T ~ 06269, ~}$ \\ United States \\ ${ }^{\mathrm{b}}$ Calera Corporation, Moss Landing, CA 95039, United States \\ *Corresponding author. Tel.: +860 4864601. \\ Email: jeff@engr.uconn.edu
}

\begin{abstract}
Closed-loop pressure retarded osmosis (PRO) has been recently proposed as a means of transforming unusable forms of energy, such as waste heat, into valuable electricity. The process, which is also referred to as an osmotic heat engine (OHE), also enables a form of osmotic grid storage for intermittently available renewable energy sources, where available energy is stored as an osmotic potential and that energy is released via PRO when energy demand is high. The OHE has the potential to generate greater power than conventional open loop PRO because the draw solution can be engineered to have very high osmotic pressures, via enhanced temperature, solute concentration, or a combination of both. These variables change fluid properties and the performance of the membrane, which may or may not be beneficial to overall OHE operation. Using a custom-built, bench-top PRO system, a commercially available forward osmosis membrane from Hydration Technology Innovations ${ }^{\mathrm{TM}}$ (HTI) was evaluated for water flux and power density at two temperatures $\left(20^{\circ} \mathrm{C}\right.$ and $\left.40^{\circ} \mathrm{C}\right)$ and three draw solution concentrations $(0.5,1.0$, and $1.5 \mathrm{M}$ sodium chloride) that are similar to temperatures and draw solution osmotic pressures capable in an osmotic heat engine. In general, power density increased with increasing draw concentration and temperature, with the highest observed power
\end{abstract}


densities $\left(18.0 \pm 2.3 \mathrm{~W} / \mathrm{m}^{2}\right)$ were measured at 20.7 bar (300 psi) using a $1.5 \mathrm{M}$ sodium chloride draw solution at $40^{\circ} \mathrm{C}$. Experimental data compared favorably to predicted performance using conventional PRO flux and power density models.

\section{Keywords}

Pressure retarded osmosis; Osmotic heat engine; Salinity gradient power; Grid storage; Energy storage

\section{Introduction}

The adoption of many carbon-neutral and renewable power technologies, such as solar or wind power, has been hindered by intermittent availability and intensity. Currently, these problems are being addressed by the development of grid storage techniques for excess power, permitting the distribution of energy during periods of high demand and energy storage during low demand periods. Batteries, compressed air, and water reservoirs have all been considered for grid storage applications, but each technology has drawbacks of either being prohibitively expensive or logistically difficult to implement [1,2].

With the advent of engineered osmosis (EO) processes, a radically different concept for grid storage has emerged based on the concept of pressure retarded osmosis (PRO) [3-5]. In 
times of energy scarcity, a PRO membrane module can be run using a concentrated solution, known as the draw, and a dilute solution, known as the feed. The draw solution is pressurized, and when water naturally flows from the dilute stream into the concentrated stream, the volume of the draw increases and work is performed. This work can be used to turn a turbine and produce electricity. Energy from a secondary source, such as waste heat or geothermal energy, can be used continuously to recover the draw and feed solutions. If energy is not available, the solutions can be stored indefinitely until energy is available for recovery.

When energy is used to concentrate the draw solution, that energy is stored in the form of osmotic potential indefinitely [6]. Depending on the properties of the chosen draw solute, the solute recovery method can vary widely. It can be be multistage distillation or gas stripping for for thermolytic solutes, or reverse osmosis and membrane distillation for non-volatile solutes [7]. For an osmotic heat engine, the energy used is thermal energy which can be used to strip a thermoytic solute or evaporate water to concentrate the solute. These concentrated draw solutions will not lose osmotic potential if properly stored, and the potential can be easily increased with additional solute [8]. These features overcome many of the limitations of other grid storage methods. Furthermore, higher water flux in the PRO step will more of the stored energy, leading to a more efficient overall process. This closed-loop energy conversion process is illustrated in Figure 1, is known as the osmotic heat engine (OHE) [9]. It is important to note that, in the case of the grid storage option outlined in Figure 1, the solute recovery system is only run to recover the draw and feed solutions when excess base-load power is available. In time of high energy demand, the solute recovery system is not run, and the stored feed and draw solutions are used by the PRO membrane element to generate power.

\section{FIGURE 1}


The OHE consists of three subsystems. The solute recycling system takes and converts it into osmotic potential. The membrane process converts the osmotic potential into hydraulic potential. The third is the hydroturbine, which converts the hydraulic potential into an electrical current. These subsystems are at various levels of development. The various methods of recovery the draw solution are generally conventional separations processes and are well developed for similar processes. Likewise, hydroturbines are well developed and understood technologies.

The membrane process, however, has only on rare occasions been demonstrated. Many of the "studies" were never published in the literature and only a handful of benchtop studies with flat sheet membrane coupons have been published. It is critical to analyze this part of the system under relevant PRO conditions, though, since the amount of energy released during a this step is related directly to the energy generating capability of the integrated system.

We often characterize this system by considering the "membrane power density". This power (or work, W) is, reported in watts per square meter of membrane area, is the maximum power available to a hydroturbine. [10,11]. It can be calculated based on equation 1 .

$$
W=\eta_{W} \Delta P
$$

In this equation, $\eta$ represents the turbine efficiency, which is often assumed to be 1 when simply evaluating membrane performance. When this equation is combined with the general water flux equation for EO, the maximum possible power density for any PRO process is generally determined as $A\left[\left(\Delta \pi^{2}\right) / 4\right]$, where $A$ is a membrane property known as the hydraulic permeance, and $\Delta \pi$ is the effective osmotic pressure gradient between the feed and draw solutions $[12,13]$. Therefore, assuming no mass transport limitations imposed by concentration polarization (CP) $[14,15]$, peak power density is a function of both osmotic pressure and membrane permeance. 
While osmotic pressure will increase with draw solute concentration, both osmotic pressure and hydraulic permeance will increase with temperature. These parameters can be tightly controlled in OHE operation, which potentially yields power densities that are not possible using PRO with seawater as the draw solution, also known as open-loop PRO [16]. The manipulation of temperature and draw concentration beyond what may occur naturally can improve the viability of osmotic energy storage using membranes that had previously been considered not suitable for PRO due to their low power density.

This study was conducted to measure the water flux and power density produced by a commercial FO membrane operated under high-concentration and elevated-temperature conditions similar to those present in an OHE. In order to assess the accuracy of the experimental results, the data was then compared to predictions generated by an established model for PRO performance. We demonstrate that even membranes that are not specifically designed for PRO applications can still operate at high power density in conditions similar to that of an OHE. This finding is relevant to OHE development because, while high flux engineered osmosis membranes are currently reported in literature, there is currently no commercially available membranes or membrane module designed specifically for PRO applications. Being able to achieve high power density with less permeable but more commercially available membranes would enable the construction of a functional OHE.

\section{Materials and methods}

\section{Materials and Chemicals}

The cellulose acetate (CA) membrane used in this study was provided by Hydration Technology Innovations ( $\mathrm{HTI}^{\mathrm{TM}}$, Albany, OR). The membrane is composed of a cellulose 
acetate active layer with an integrated woven mesh support layer. These membranes have been used as a benchmark in prior studies of FO [17]. Water was provided by an Integral 10 water system (Millipore Corporation, Billerica, MA).

Sodium chloride was purchased from Fisher Scientific (Pittsburgh, PA). Sodium chloride was selected as the test draw solute for this study. While sodium chloride would not be an ideal solute in an actual OHE, the draw solutes can still be thermally recovered by evaporation or physically recovered by reverse osmosis. Sodium chloride was also selected for this study because is highly solubile and stable in water. Therefore, high draw solute osmotic pressures are possible at a wide range of concentrations and temperatures. Furthermore, sodium chloride was also used in the previously mentioned characterization study [17], which provides a point of comparison for the current study.

\section{Bench-Scale PRO system}

A benchtop PRO system was used to measure water flux and salt flux under true PRO conditions on the coupon scale. Both the feed and draw solution were temperature controlled using a recirculating chiller/heater (Fisher Scientific, Waltham, MA). Draw, feed, and draw bypass streams were circulated counter-currently though a custom membrane cell with channel dimensions of 3 inches long by 1 inch wide by $1 / 8$ inch deep $(7.6 \mathrm{~cm}$ by $2.5 \mathrm{~cm}$ by $0.3 \mathrm{~cm})$. The feed channel was completely filled with several layers of pre-wet Tricot mesh support in order to prevent membrane deformation when the draw solution is pressurized. The membrane was sealed in the cell using a PVDF gasket (McMaster, Princeton, NJ) around the channel on the feed half of the cell and a PVDF o-ring (McMaster) embedded around the channel on the draw side of the cell. A proper seal with the correct amount of tricot ensured that the cell would not leak and 
that the membrane would not be bypassed. Water flux was measured gravimetrically using a balance (Denver Instruments PI-4002, Denver Instruments, Bohemia, NY) and data acquisition software. A conductivity probe and thermometer were placed into the feed tank to monitor solution conductivity and temperature. A diagram of the complete system is located in Figure 2.

\section{FIGURE 2}

Fresh membrane samples were tested in triplicate using the PRO orientation (describe elsewhere as AL-DS) [18] and evaluated at two temperatures: $20^{\circ} \mathrm{C}$ and $40{ }^{\circ} \mathrm{C}$ (for both draw and feed solutions). At each of these temperatures, three draw solutions of $0.5 \mathrm{M}, 1.0 \mathrm{M}$, and 1.5 M sodium chloride $(\mathrm{NaCl})$ were tested. The feed stream was deionized water for all tests. Stream flow rates for the feed and draw were maintained at $1 \mathrm{~L} / \mathrm{min}(0.25 \mathrm{~m} / \mathrm{s})$ and $2 \mathrm{~L} / \mathrm{min}(0.5$ $\mathrm{m} / \mathrm{s}$ ), respectively. For each draw solution, pressure was increased from 3.45 bar (50 psi) to 20.6 bar (300 psi) in 3.45 bar increments. Once maximum pressure was achieved, the pressure was then reduced in 3.45 bar increments to assure that flux had not changed as a result of highpressure membrane deformation. Each pressure was maintained for 10-15 minutes while data was collected. Feed solution conductivity was measured following each change in pressure.

\section{Determination of Model Parameters}

The experimental data was compared to data generated using the equation derived by Yip and Elimelech in order to assess its accuracy [19]. The model accounts for both concentrative and dilutive external concentration polarization (ECP) on the feed side and draw side of the membrane, respectively, and concentrative internal concentration polarization (ICP). As ICP is usually the greatest mass transport limitation in osmotically-driven flow across asymmetric membranes in most closed-loop PRO processes, ECP on the feed side can be neglected if feed 
concentration is low [13]. The model generated water flux and power density data assuming constant draw solution concentration and negligible feed solution concentration. Mass transfer coefficients for the solutions were determined using Reynolds, Schmidt, and Sherwood number correlations [20].

Reverse osmosis (RO) tests of the HTI CA membrane were performed to evaluate hydraulic permeance $(A)$ and solute permeability $(B)$ membrane at both $20^{\circ} \mathrm{C}$ and $40^{\circ} \mathrm{C}$, as both $A$ and $B$ are expected to increase as temperature increases. Membranes were tested in a lab-scale crossflow RO system at a cross-flow velocity of $0.25 \mathrm{~m} / \mathrm{s}$. The channels of the membrane cells had the same dimensions as the channel in the PRO membrane cell. The system design is described in a previous paper by the authors [21]. RO tests were conducted with fresh membrane samples operating at temperatures of $20^{\circ} \mathrm{C}$ and $40^{\circ} \mathrm{C}$. To measure water permeance, water flux through the membranes was collected at pressures of 8.6, 15.5, 22.4, and 29.3 bar. Salt rejection tests were conducted with a feed of 2000 parts per million (ppm) sodium chloride at a pressure of 15.5 bar. The conductivity of permeate and feed were measured to determine the rejection. Solute permeability for the membrane was determined using the water flux and intrinsic rejections for the $\mathrm{RO}$ test.

Calculated structural parameter $(S)$ values were taken from a multiple-laboratory characterization of the FO membrane used in this study [17]. While the tests in that previous study were performed at $20^{\circ} \mathrm{C}$, these $S$ values will be valid at any temperature, as $S$ depends on membrane characteristics that are independent of temperature $[15,22]$. The previous study reported structural parameters that ranged from 425 to $675 \mu \mathrm{m}$, so these values were used to determine a high flux $(S=425 \mu \mathrm{m})$ and low flux $(S=675 \mu \mathrm{m})$ condition for the performance of 
these membranes. The experimental data should fall in the area between the high flux and low flux curves.

\section{Results and discussion}

Water Permeance and Salt Permeability

Water permeance and solute permeability data are shown in Table 1 for all of the temperatures evaluated in this study.

\section{TABLE 1}

As anticipated, increasing temperature caused both $A$ and $B$ to increase since as temperature increased, both water and solutes permeate the membrane more easily. The increase between the two temperatures is significant based on the standard deviation error limits. The $20^{\circ} \mathrm{C}$ values are also within the range reported previously [17].

\section{PRO Performance}

Figure 3 summarizes the water flux data for $0.5 \mathrm{M}, 1.0 \mathrm{M}$, and $1.5 \mathrm{M} \mathrm{NaCl}$ draw solutions at $20^{\circ} \mathrm{C}$ and $40^{\circ} \mathrm{C}$ tested under actual PRO conditions. It is important to note that a positive flux is denoted by water traveling from the draw solution into the feed. Thus, a negative flux is reported when water travels from the feed to the draw and is desirable for PRO.

\section{FIGURE 3}

Water flux increased with increasing draw solution concentration (higher driving force) and temperature (higher water permeance, enhanced mass transfer. As hydraulic pressure was increased for all temperatures and concentrations, the net water flux decreased. This is expected based on equation 1. 
Figure 4 illustrates power density as a function of draw solution pressure for the three draw solutions at $20{ }^{\circ} \mathrm{C}$ and $40{ }^{\circ} \mathrm{C}$. At constant temperature and concentration, increasing hydraulic pressure causes power density to increase and reach a maximum. This peak power density is visible in the data for the $0.5 \mathrm{M}$ draw solutions. At constant pressure, conditions that yield high net water flux (either high draw solution concentration or high temperature) also yield high power density.

\section{FIGURE 4}

The $0.5 \mathrm{M}$ draw solution data has an interesting feature. A flux inversion point occurs, indicating the pressure at which osmotic equilibrium exist and the process transitions from PRO to RO. Equation 1 predicts that this will occur when the hydraulic pressure applied equals the osmotic pressure of the draw solution. However, this data shows otherwise. The bulk draw solution has an osmotic pressure of approximately 24.3 bar at $20^{\circ} \mathrm{C}$ and 26.0 bar at $40{ }^{\circ} \mathrm{C}$. The actual flux inversion point for the experimental data is approximately 20.5 bar at $20{ }^{\circ} \mathrm{C}$. For the $40{ }^{\circ} \mathrm{C}$, the data was extrapolated to estimate a flux inversion point at 22.5 bar. Both of these flux inversion points are substantially lower than expected values.

This discrepancy is explained by salt crossing the membrane. While this salt does not contribute to the osmotic pressure, a more substantial problem is internal concentration polarization, which increases the salt concentration on the opposite side of the selective layer. At zero flux, salt is free to diffuse through the selective layer and accumulate in the support layer. This effect dramatically lowers the transmembrane osmotic pressure and thus lowers the pressure at which peak power density and osmotic equilibrium occurs [23].

Salt flux into the feed is shown as a function of operating pressure for $20^{\circ} \mathrm{C}$ in Figure 5 (a) and for $40^{\circ} \mathrm{C}$ in Figure 5(b). Although the differences between the data sets are not statistically 
significant based on the large error bars. Even so, there are general upward trends in salt flux with increasing applied pressure. The upward trend in salt flux generally becomes more visible as the draw solution concentration increases. This trend is likely caused by reduced dilutive ECP in the draw solution as net water flux decreases. Lower water flux into the draw solution would diminish the dilutive ECP boundary layer, which would cause the concentration at the draw-side membrane interface to increase. The resulting change in interface concentration would case greater reverse salt flux into the feed solution. Additionally, at elevated temperatures, greater salt fluxes are likely observed due to the increased salt diffusivity. Higher diffusivity allows the salt to permeate the membrane more readily than it would at lower temperatures.

\section{FIGURE 5}

\section{Comparison of simulated and experimental data}

A comparison of the experimental and simulated data for all tested draw solutions at $20^{\circ} \mathrm{C}$ and $40^{\circ} \mathrm{C}$ is shown in Figure 6. Experimental flux data is indicated by solid points, and experimental power density is indicated by hollow points. Each data set has two lines predicting the performance of the membrane in PRO under the same temperature and solution conditions. The lower flux and power density predictions (both closer to the x-axis) are made using the high structural parameter value $(S=675 \mu \mathrm{m})$. The other prediction lines, which are both further from the x-axis, assumes a low structural parameter $(S=425 \mu \mathrm{m})$. The lines represent different concentrations of draw solution (solid lines representing $0.5 \mathrm{M}$, dashed lines representing 1.0 M, and dotted lines representing $1.5 \mathrm{M})$.

The trends in the data are supported by the predicted equation proposed by Yip \& Elimelech [19]. Some offset in the data can be explained by small, systematic variations in the 
system, small differences in the coupons themselves, or feed channel support compaction. As draw pressure increases, the membrane is forced against the tricot support, which may reduce the area of the membrane available for flux. This area reduction will reduce the observed water flux and observed power density, which may explain the lower experimental power density.

\section{FIGURE 6}

In general, operating at a higher temperature yields substantially higher power densities.

For instance, the model predicts greater power density at elevated temperatures, as membrane hydraulic permeance, solute diffusivity, and draw osmotic pressure all increase with temperature. The data shows that peak experimental power density of the $0.5 \mathrm{M}$ sodium chloride draw solution change from $1.3 \pm 0.6 \mathrm{~W} / \mathrm{m}^{2}$ at $20^{\circ} \mathrm{C}$ to $4.0 \pm 0.9 \mathrm{~W} / \mathrm{m}^{2}$ at $40^{\circ} \mathrm{C}$, which is approximately a $300 \%$ increase in power density. The effect of temperature is more pronounced at greater draw solution concentrations. For the 1.5 M sodium chloride draw solution, the peak experimental power density is elevated from $8.8 \pm 1.0 \mathrm{~W} / \mathrm{m} 2$ at $20^{\circ} \mathrm{C}$ to $18.0 \pm 2.3$ at $40^{\circ} \mathrm{C}$. However, these power densities were observed at a hydraulic pressure of 20.7 bar, which is the limit of the bench-top system and far from the peak power density predicted by the equations. If operated at peak power density with a $1.5 \mathrm{M}$ draw solution, the predictions shown in Figure 6 indicate that this membrane could produce up to $12.5 \mathrm{~W} / \mathrm{m}^{2}$ at $20^{\circ} \mathrm{C}$ and up to $25.0 \mathrm{~W} / \mathrm{m}^{2}$ at $40^{\circ} \mathrm{C}$.

The data suggests that high power density PRO is possible with currently available FO membranes, provided they are operated at elevated temperature and pressure. The use of membranes with greater inherent hydraulic permeance (such as a thin-film composite membrane) will naturally yield even higher power density. However, the OHE operating conditions show promise for the future of osmotic power, allowing membranes that were not designed expressly for PRO to exhibit high power density. 


\section{Conclusions}

The recent decline in industrial interest in seawater-river water open-loop PRO is a revealing story. Fouling from natural waters, limited osmotic pressure in seawater, and geographic restrictions are all substantial, and perhaps insurmountable, obstacles to this type of osmotic power. The OHE avoids all of these limitations, requiring either low temperature heat or an intermittent renewable energy source, to operate. In this work, we have successfully demonstrated typical conditions of OHEs will in fact produce far higher power densities than conventional open-loop PRO using a commercially available FO membrane. Future work on this subject will further prove that a system like the OHE, which decouples the PRO step and the draw solute regeneration, may in fact also be useful for grid storage applications. To make such an osmotic grid storage system a reality, the obstacles such as overall process efficiency must be overcome. While membrane selectivity and robustness must be improved to yield high power density, system and module design and draw solution recovery strategies must also be established for appropriate energy sources. Further studies with other draw solute options, such as those able to be recovered thermally, is necessary to determine how these solutes will perform in similar conditions, but the general trends in the data are expected to be similar. Focusing on membranes alone will not achieve the goal of a fully functional OHE system.

\section{Acknowledgements}

The authors would like to acknowledge the Department of Energy (DE-EE00003226) and the University of Connecticut Chemical \& Biomolecular Engineering Department, Office of Undergraduate Research Summer Undergraduate Research Fund, and the Robert \& Beatrice 
Mastracchio Endowed Scholarship for providing funding for this work. Hydration Technology

Innovations graciously supplied membranes for this study.

\section{References}

[1] Testimony of Sean Casten President, Recycled Energy Development Chairman, U.S. Clean Heat and Power Association Before the Energy, Natural Resources, and Infrastructure Subcommittee Of the Senate Finance Committee: Energy Efficiency: Can Tax Incentives Reduce Consumption? (2007) (testimony of Sean Castin). 24 May 2007. Web. 29 Jan 2010.

[2] A. Cavallo, "Controllable and Affordable Utility-scale Electricity from Intermittent Wind Resources and Compressed Air Energy Storage (CAES)"Energy 32 (2007) 120-7

[3] S. Loeb, "Production of Energy from Concentrated Brines by Pressure-Retarded Osmosis: I. Preliminary Technical and Economic Correlations"Journal of Membrane Science 1 (1976) 49-63.

[4] S. Loeb, F. Van Hassen, D. Shahaf,"Production of Energy from Concentrated Brines by Pressure-Retarded Osmosis: II. Experimental Results and Projected Energy Costs"Journal of Membrane Science1, (1976) 249-69.

[5] A. Achilli, T.Y. Cath, A.E. Childress, "Power Generation with Pressure Retarded Osmosis: An Experimental and Theoretical Investigation"Journal of Membrane Science343 (2009) 4252.

[6] R.A. Robinson, R.H. Stokes, Electrolyte Solutions. $2^{\text {nd }}$ Ed. (2002)

[7] J.R. McCutcheon, R.L. McGinnis, M. Elimelech, "A Novel Ammonia-Carbon Dioxide Forward (Direct) Osmosis Desalination Process"Journal of Membrane Science 174 (2005) 111.

[8] R. McGinnis, A. Mandell, “Utility Scale Osmotic Grid Storage.” Patent WO 2010065791 A3. 17 March 2011.

[9] R.L. McGinnis, J.R. McCutcheon, M. Elimelech, "A Novel Ammonia-Carbon Dioxide Osmotic Heat Engine for Power Generation” Journal of Membrane Science 305 (2007) 13-9.

[10] K.L. Lee, R.W. Baker, H.K. Lonsdale,"Membranes for Power generation by Pressure Retarded Osmosis"Journal of Membrane Science 8 (1981) 141-71.

[11] A. Achilli, A.E. Childress, "Pressure retarded osmosis: From the vision of Sidney Loeb to the first prototype installation" Desalination 261 (2010) 205-211

[12] R.L. McGinnis, M. Elimelech, "Global Challenges in Energy and Water Supply: The Promise of Engineered Osmosis"Environmental Science and Technology 42 (2008) 8625-9.

[13] T.Y. Cath, A.E. Childress, M. Elimelech, "Forward Osmosis: Principles, Applications, and Recent Developments" Journal of Membrane Science 281 (2006) 70-87.

[14] J.R. McCutcheon, M. Elimelech, "Influence of Concentrative and Dilutive Internal Concentration Polarization on Flux Behavior in Forward Osmosis" Journal of Membrane Science 284 (2006) 237-47

[15] J.R. McCutcheon, M. Elimelech, "Modeling Water Flux in Forward Osmosis: Implications for Improved Membrane Design" AIChE Journal 53 (2007) 1736-44 
[16] N.Y. Yip, M. Elimelech, "Thermodynamic and Energy Efficiency Analysis of Power Generation from Natural Salinity Gradients by Pressure Retarded Osmosis" Environmental Science and Technology 46 (2012) 5320-39

[17] T.Y. Cath, M. Elimelech, J.R. McCutcheon, R.L. McGinnis, A. Achilli, D. Anastasio, A.R. Brody, A.E. Childress, I.V. Farr, N.T. Hancock, J. Lampi, L.D. Nghiem, M. Xie, N.Y. Yip. "Standard Methodology for Evaluating Membrane Performance for Osmotically Driven Membrane Processes" Desalination 312 (2013) 31-38

[18] G.T. Gray, J.R. McCutcheon, M. Elimelech, "Internal Concentration Polarization in Forward Osmosis: Role of Membrane Orientation" Desalination197 (2006) 1-8 [19] N.Y. Yip, M. Elimelech "Performance Limiting Effects in Power Generation from Salinity Gradients by Pressure Retarded Osmosis.” Environmental Science \& Technology 45 (2011) 10273-82

[20] M. Mulder, Basic Principles of Membrane Technology, $2^{\text {nd }}$ Ed. (1996)

[21] D. Anastasio, J.R. McCutcheon, "Teaching Mass Transfer and Filtration Using Crossflow Reverse Osmosis and Nanofiltration: An Experiment for the Undergraduate Unit Operations Laboratory." Chemical Engineering Education 46 (2012) 19-28

[22] S. Loeb, L. Titelman, E. Korngold, J. Freiman, "Effect of Porous Support Fabric on Osmosis through a Loeb-Sourirajan Type Asymmetric Membrane" Journal of Membrane Science 129 (1997) 243-9

[23] N.N. Bui, J.R. McCutcheon, "Nanofiber Supported Thin-film Composite Membrane for Pressure Retarded Osmosis" Environmental Science \& Technology 48 (2014) 4129-36 
Figures

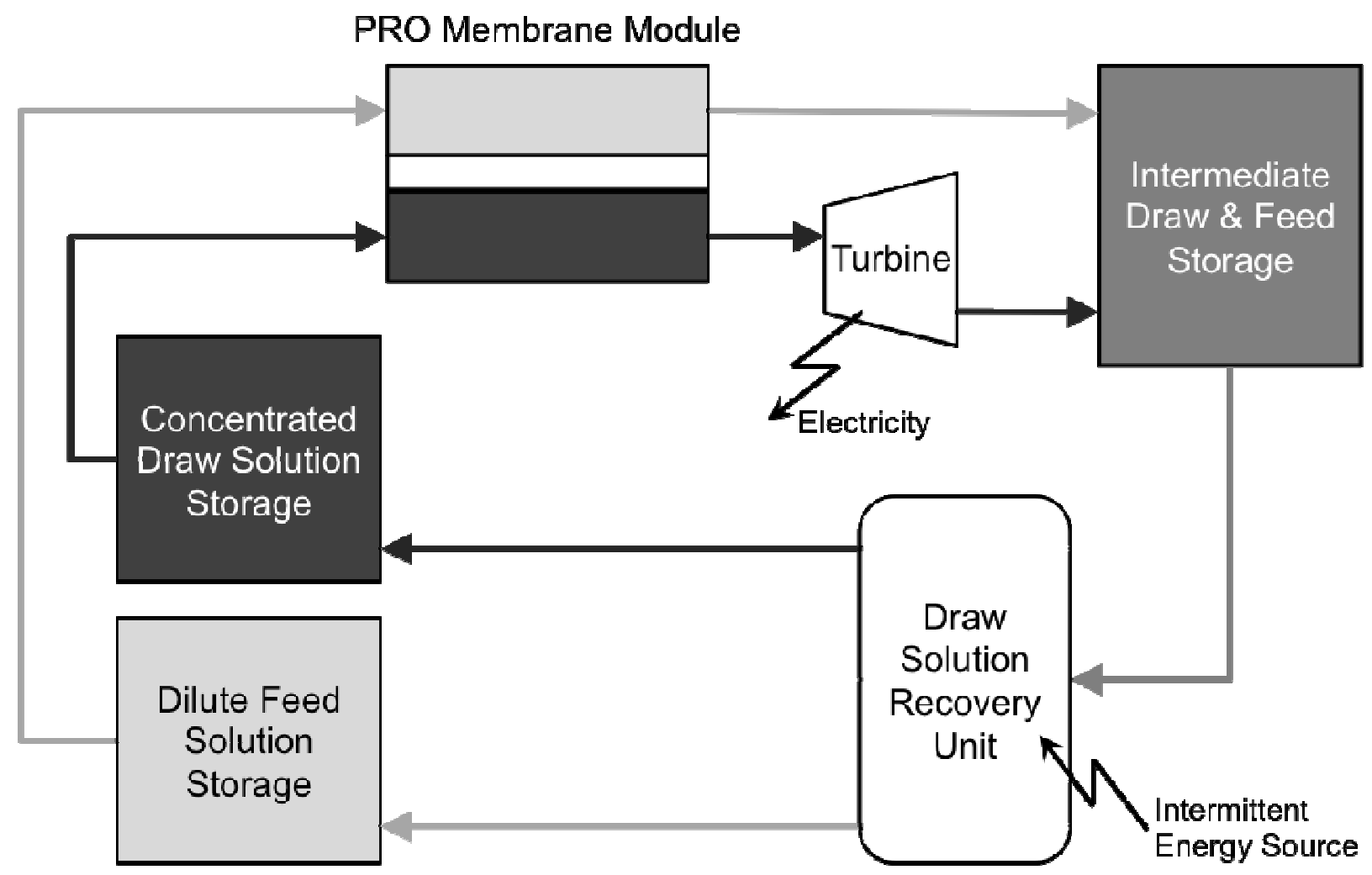

Figure 1: Schematic for an osmotic heat engine used as part of an osmotic grid storage system. The draw solution recovery unit operates when energy is available, and the PRO membrane module operates when energy is in demand (pressure exchanger to maintain draw solution pressure is not shown). 


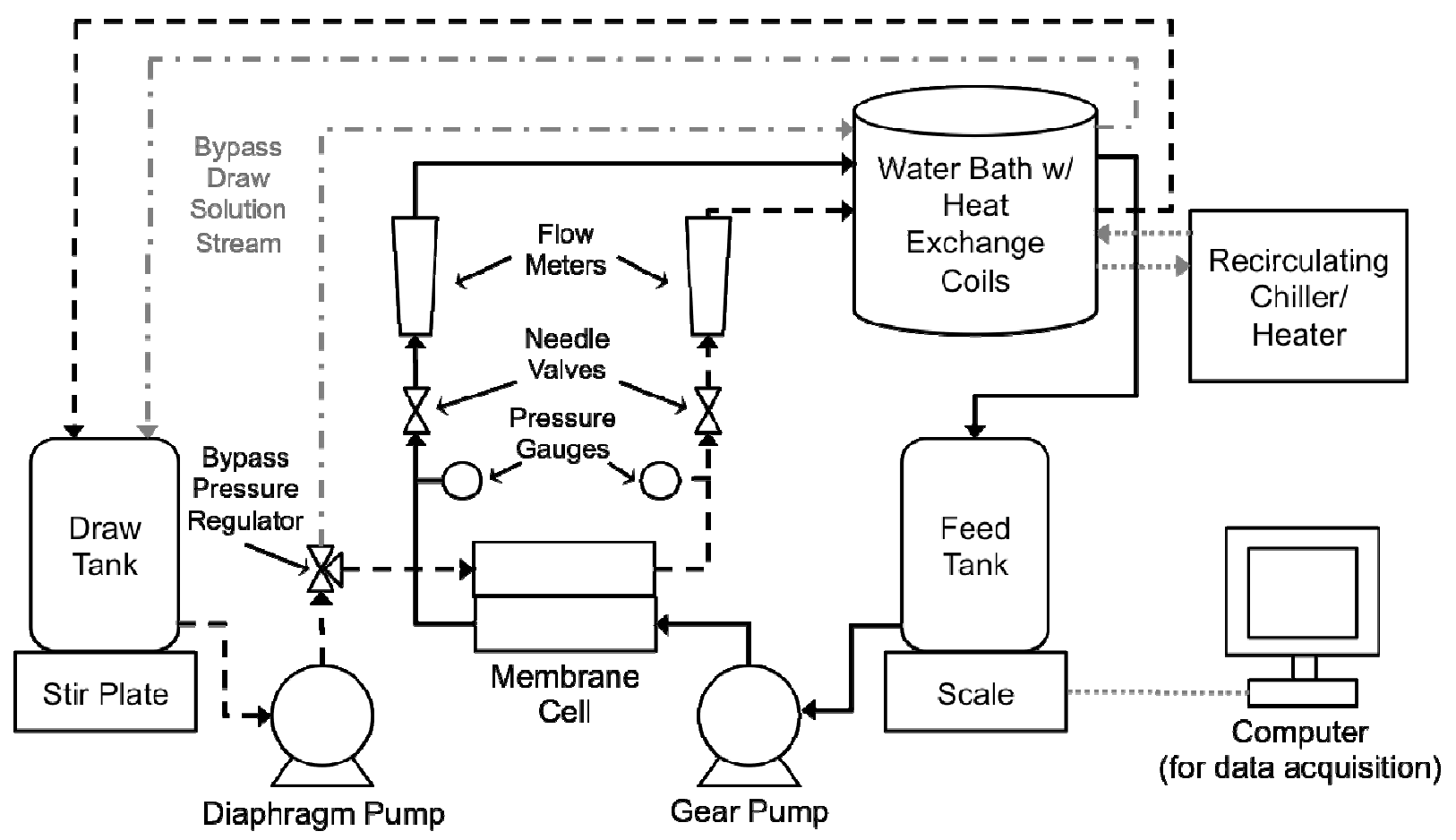

Figure 2: Schematic of the bench-top PRO system 


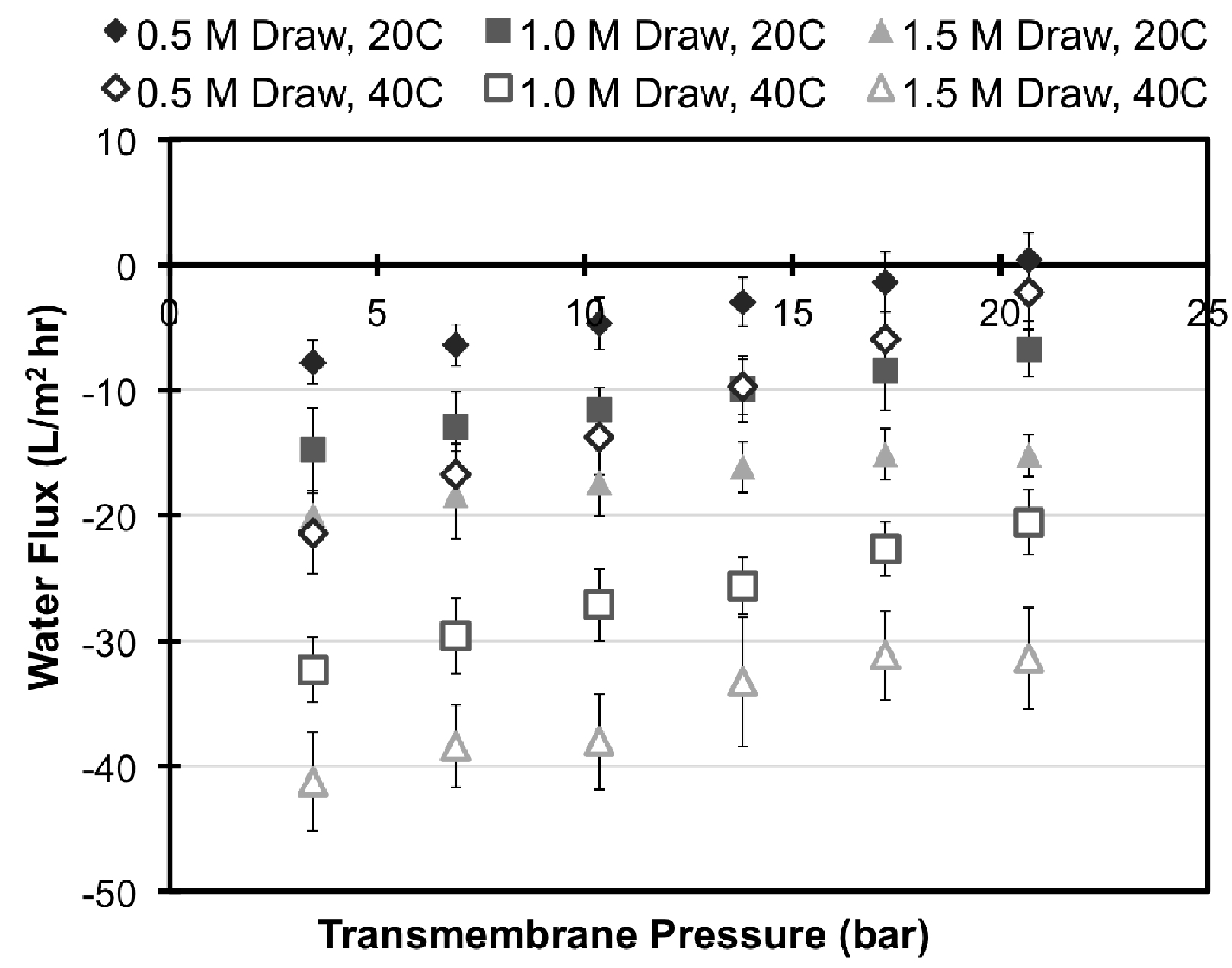

Figure 3: Experimental water flux of the HTI cartridge membrane as a function of draw solution pressure for 20 and $40{ }^{\circ} \mathrm{C}$ and draw solution chemistries. Draw solute was sodium chloride. Draw flow velocity was $0.5 \mathrm{~m} / \mathrm{s}$, Feed flow velocity was $0.25 \mathrm{~m} / \mathrm{s}$. Error bars indicate standard deviation of three trials. 


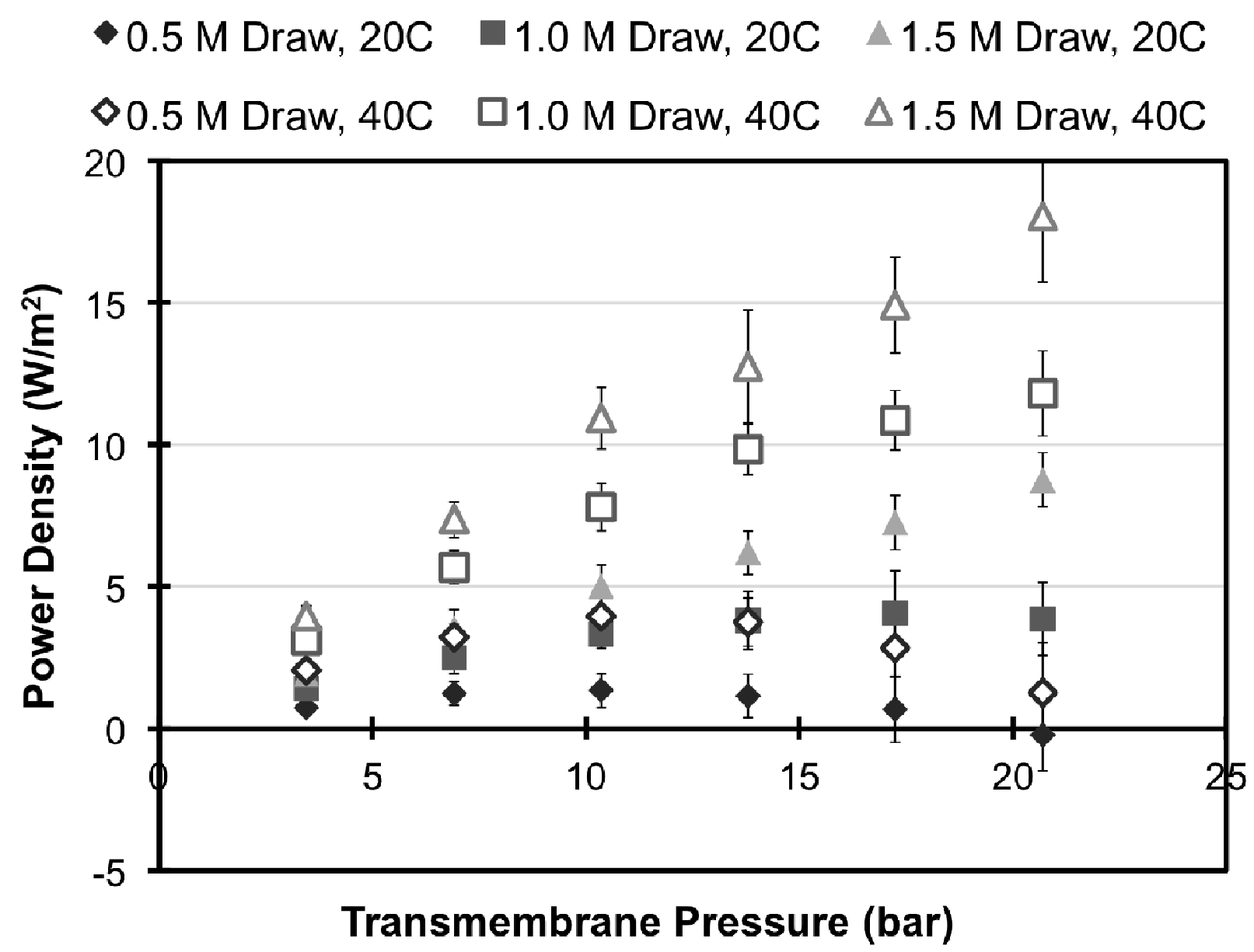

Figure 4: Experimental power density of the HTI cartridge membrane as a function of draw solution pressure for 20 and $40{ }^{\circ} \mathrm{C}$ for various draw solution compositions. Draw solute was sodium chloride. Draw flow velocity was $0.5 \mathrm{~m} / \mathrm{s}$. Feed flow velocity was $0.25 \mathrm{~m} / \mathrm{s}$. Error bars indicate standard deviation of three trials. 
(a)

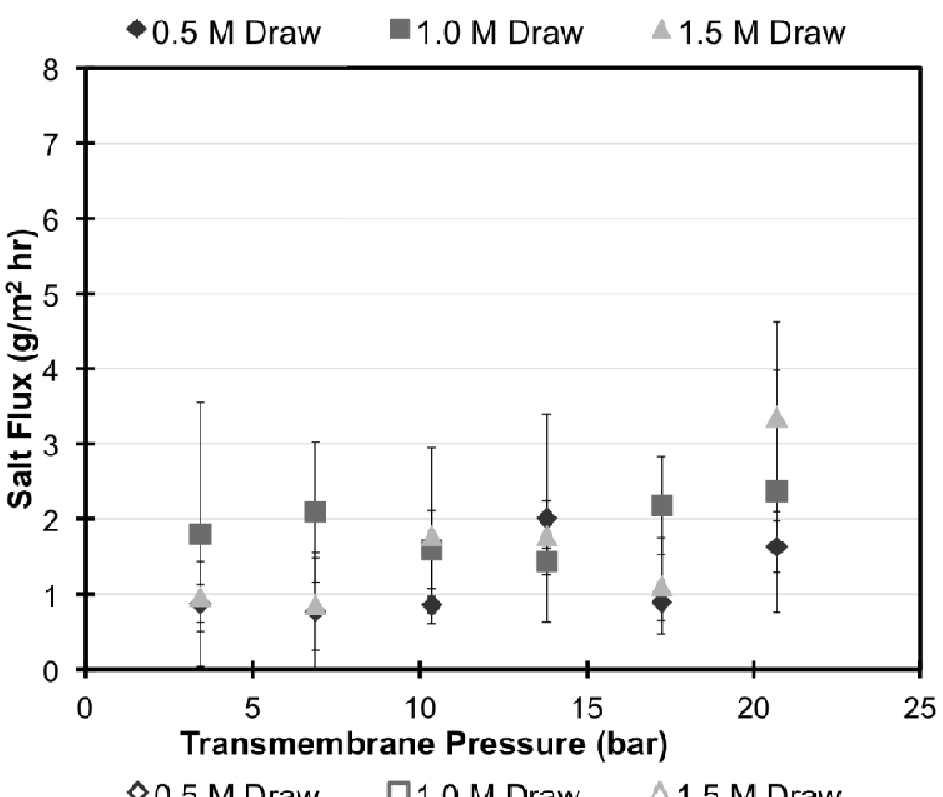

(b)

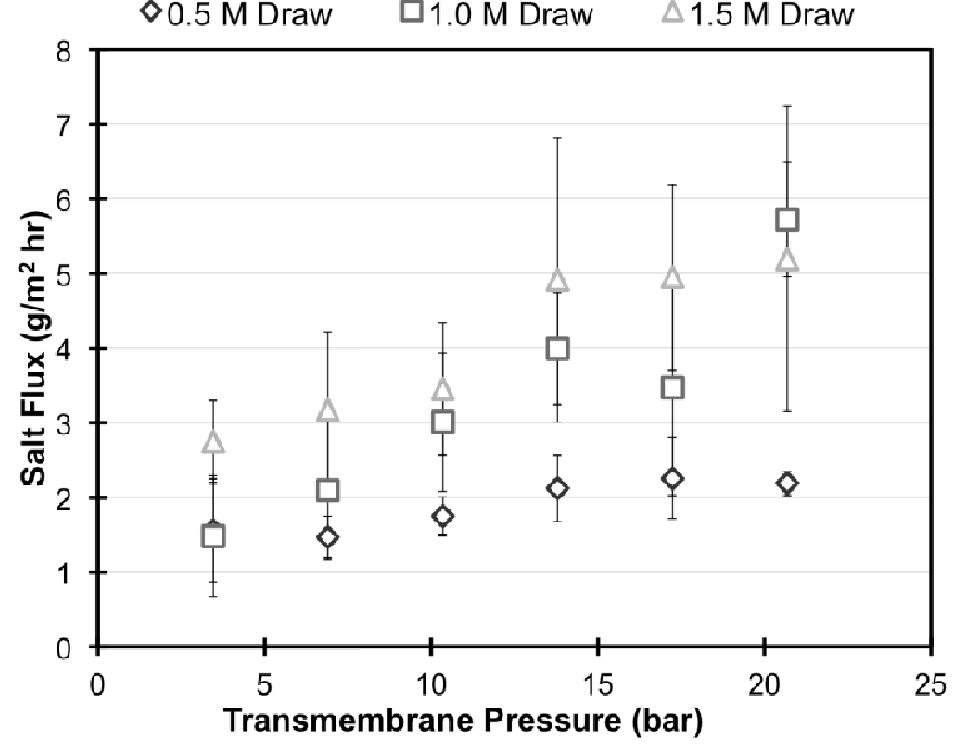

Figure 5: Observed average salt flux for the HTI cartridge membrane at $20^{\circ} \mathrm{C}$ (a) and $40{ }^{\circ} \mathrm{C}$ (b) for $0.5,1.0$, and $1.5 \mathrm{M}$ draw solutions at various pressures. Salt was sodium chloride. Draw flow velocity was $0.5 \mathrm{~m} / \mathrm{s}$. Feed flow velocity was $0.25 \mathrm{~m} / \mathrm{s}$. Error bars indicate the standard deviation of three trials. 
(a)

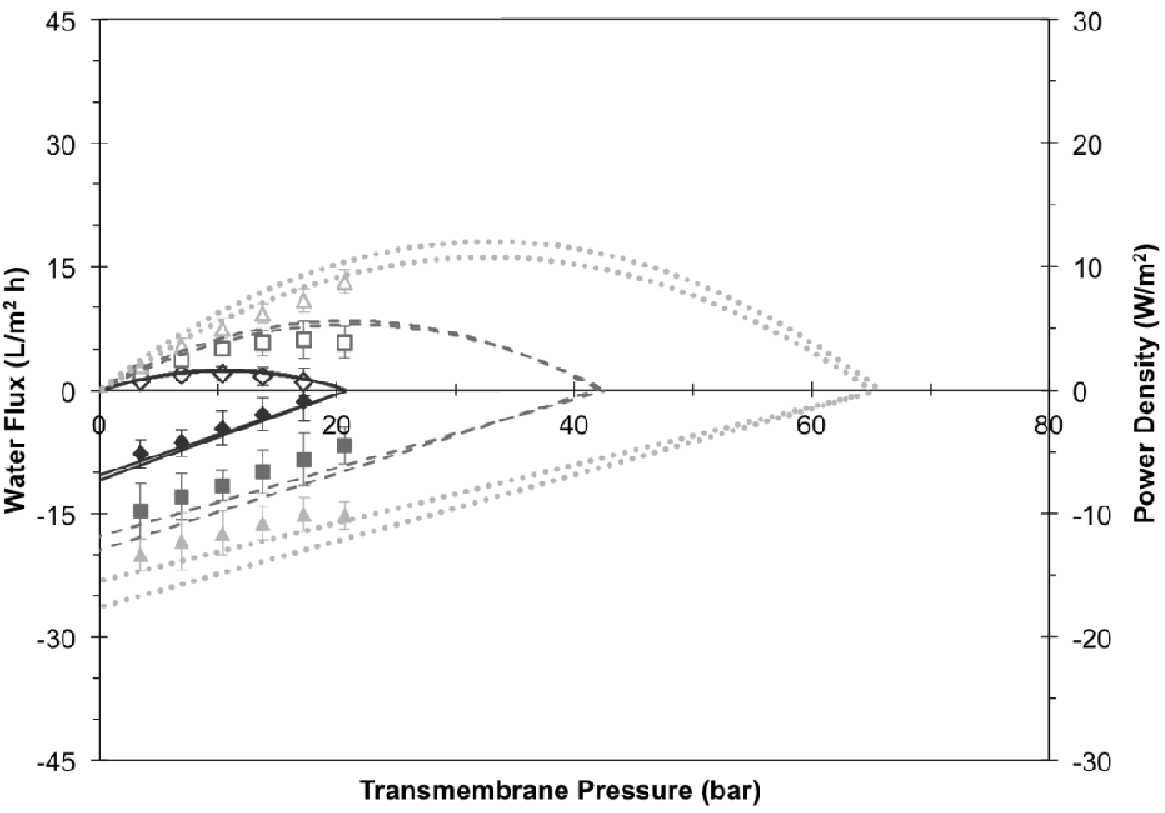

(b)

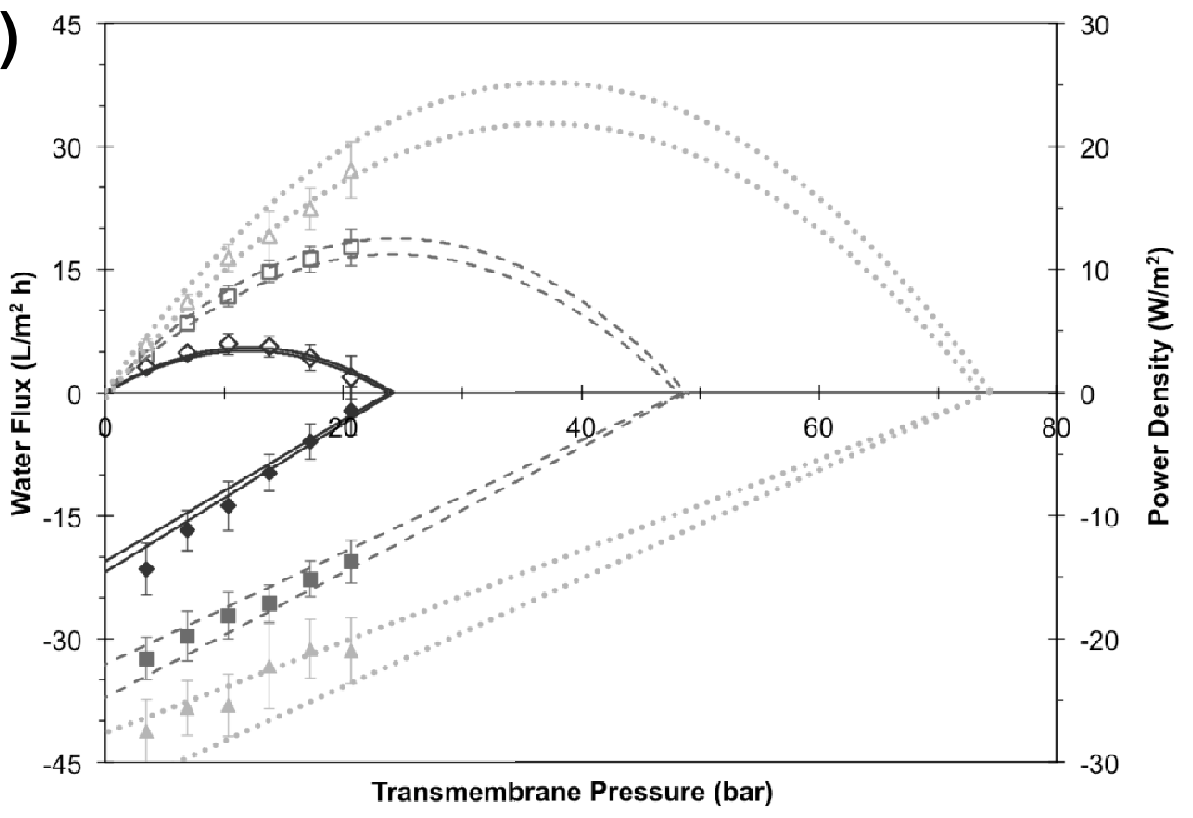

Figure 6: Model and experimental water permeability (solid points) and power density (hollow points) at $20{ }^{\circ} \mathrm{C}$ (a) and $40{ }^{\circ} \mathrm{C}$ (b). Lines indicate the model and points indicate experimental data. Error bars are standard deviation. Diamond points and solid lines indicate $0.5 \mathrm{M}$ draw, square points and dashed lines indicate 1.0M draw, and triangle points and dotted lines indicate 1.5 $\mathrm{M}$ draw. Area between the lines indicates range of anticipated values. 


\section{Graphical Abstract}

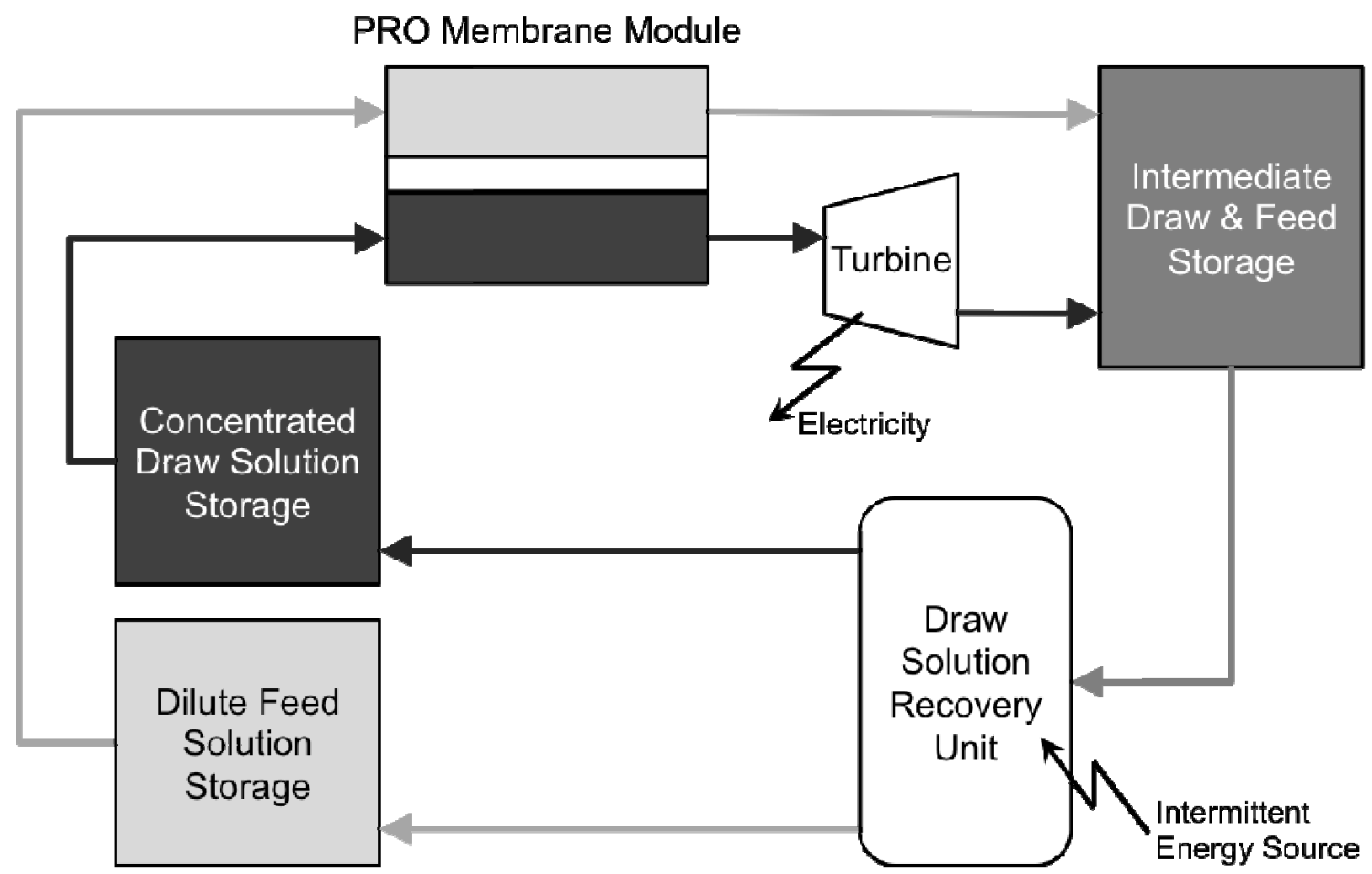

Table

Table 1: $A$ and $B$ parameters for HTI FO membrane based on RO tests with 2000 ppm sodium chloride feed

\begin{tabular}{|c|c|c|}
\hline $\begin{array}{c}\text { Temperature } \\
\left({ }^{\circ} \mathrm{C}\right)\end{array}$ & $\begin{array}{c}\text { Water Permeance, } A \\
(\mathrm{LMH} / \mathrm{bar})\end{array}$ & $\begin{array}{c}\text { Solute Permeability, } B \\
(\mathrm{LMH})\end{array}$ \\
\hline 20 & $0.589 \pm 0.009$ & $0.319 \pm 0.041$ \\
\hline 40 & $1.12 \pm 0.05$ & $0.580 \pm 0.119$ \\
\hline
\end{tabular}

